\title{
A Prospective Study on Evaluation of Efficacy of Combination Therapy of Tamsulosin and Deflazacort In Ureteric Stone Expulsion
}

\author{
E.Sam Jeeva Kumar ${ }^{1^{*}}$,Amitha Mary Samson ${ }^{2}$, Avani S L ${ }^{2}$, Pranith $\mathrm{P} \mathrm{L}^{2}$, \\ Catherine Samantha ${ }^{2}$, Dr.Prasobh $\mathbf{G ~ R}^{\mathbf{3}}$ \\ 1.Department of Pharmacy Practice, Sree Krishna College of Pharmacy and Research Centre, \\ Thiruvananthapuram, Kerala, India
}

\begin{abstract}
The patients with ureteric stone are increasing day by day all over the world. A ureteric stone is a mineral mass in the ureter which may or may not originated in the kidney and travelled down to the ureter. The presence of stone in ureter causes inflammation and edema. There are mainly four types of ureteric stone such as Calcium stones, Uric acid stones, Struvite stone, Cystine stone. About 23-53\% of spontaneous stone expulsion occurs where the size of stone is $5-10 \mathrm{~mm}$ diameter. Tamsulosin is an alpha 1 adrenergic blocker which has a spasmolytic action and thus hasten stone expulsion. Deflazacort is a corticosteroid prodrug which acts on the glucocorticoid receptor to show an anti-inflammatory effect. Deflazacort decreases the edema and when prescribed along with alpha 1 adrenergic receptor blocker it facilitate the expulsion of calculi. This study was conducted in 20 patients diagnosed with ureteric calculi. The study was conducted by using suitable proforma for collecting various data's like site of stones, presence of hydronephrosis, signs and symptoms. Health related quality of life of the patients with ureteric calculi under the treatment of Tamsulosin and Deflazacort combination were assessed by using Wisconsin Stone-QOL questionnaire. As counselling aid patients information leaflet was provided. The patients were asked to review after 10 days of taking the medication. At the end of the study all the parameters and scores were compared with baseline to the end of the study. In our study we analyzed that the data collected from 20 patients diagnosed with ureteric calculi accessed the improvement of quality of life of patients under the treatment of Tamsulosin and Deflazacort combination by using Wisconsin Stone-QOL questionnaire. The observed difference before and after the treatment with Tamsulosin and Deflazacort was statistically significant $(\mathrm{p}<0.05)$. It is found that there was a significant improvement in the quality of life of the patient after combination treatment with Tamsulosin and Deflazacort. By evaluating this pilot study, we conclude that the medical expulsive therapy using Tamsulosin and Deflazacort combination is a first line therapy in management of ureteric stones. It is also found that the combination therapy of Tamsulosin and Deflazacort have good expulsion rate.
\end{abstract}

Keywords: Tamsulosin and Deflazacort, ureteric stone 


\section{INTRODUCTION}

A ureteric stone is a mineral mass seen in ureter which may or may not be originated in the kidney and then travelled down to the ureter. The stone is formed by the deposition of small grain of solid particles in the kidney. It is found that about $70 \%$ of stone is formed in the lower third of ureter. The spontaneous stone passage depends upon the initial stone location and size of the stone. About 23-53\% of spontaneous stone expulsion occurs where the size of stone is 5$10 \mathrm{~mm}$ diameter. There are various methods for removing the stone depending up on size and site of stone. ${ }^{(1)}$

Types

There are mainly four types of ureteric stone

- Calcium stones

- Uric acid stones

- Struvite stone

- Cystine stones

\section{Etiology}

There is no single factor can predict the likelihood of developing ureteric stone although there are many studies linking a particular factor to an increased risk of urinary stone formation. The low fluid intake will result in decreased urine production and also produce subsequent high concentration of stone forming salts. ${ }^{(2)}$

Calcium stone is associated with Hypercalciuria. The increased level of calcium can be due to medical conditions such as hyperparathyroidism ${ }^{(3)}$, hypercalcemia of malignancy ${ }^{(4)}$ increased absorption of calcium from the gut ${ }^{(5)}$. Hypercalciuria can also be associated with medication such as thiazide diuretics.

Struvite Stone is associated with approximately $15 \%$ of all kidney stones. Combination of ammonia and alkaline urine is required for the formation of a Struvite stone. The splitting of urea by urease (enzymes produced by colonized bacteria) Pseudomonas, Staphylococcus, Proteus, Klebsiella $^{(6)}$ are the common urease-producing bacterias. Women or patients with anatomic abnormalities who are predispose to recurrent urinary tract infection are at an increased risk of developing struvite stones.

\section{Uric Acid Stones}

$6 \%$ of kidney stones are uric acid stone. The formation of uric acid stone is associated with hyperuricosuria, with low urine $\mathrm{pH}$ being the most important factor, urine volume, low urinary $\mathrm{pH}^{(7)}$. Risk factors for uric acid stone include hypertension, diabetes mellitus, and obesity ${ }^{(8,9)}$ 


\title{
Cystine stones
}

Cystine stones occur mainly due to cystinuria, an inherited disorder of the transport of an amino acid called Cystine, which results in excess amount of cystine in the urine (cystinuria) and thus leads to formation of cystine stones. The formed cystine then tends to precipitate out of the urine and form stones (calculi) in the urinary tract. Small stones will pass through urine, while big stones remain in the kidney (nephrolithiasis) impair the outflow of urine and medium-size stones move from the kidney into the ureter and lodge there, which blocks the flow of urine. The obstruction on urinary tract puts pressure on both the ureter and kidney causing the ureter to dilate and thus the kidney to be compressed. Obstruction also causes the urine to be stagnant which an open invitation for repeated urinary tract infection ${ }^{(10)}$

\section{Diagnosis}

- Urinalysis ${ }^{(2)}$

It is used for detecting presence of red blood cells, white blood cells, protein, crystals

\author{
- $\quad$ Radiographic studies ${ }^{(2)}$ \\ $\checkmark \quad$ Kidney /ureter/ bladder X-ray (KUB X-ray) \\ $\checkmark \quad$ Intravenous pyelogram \\ $\checkmark \quad$ Ultrasonography \\ $\checkmark \quad$ Non enhanced helical computed tomography \\ - $\quad$ Laboratory studies ${ }^{(2)}$ : \\ $\checkmark \quad$ Complete blood count (CBC) \\ $\checkmark \quad$ Blood urea nitrogen (BUN) \\ $\checkmark \quad$ Creatinine \\ $\checkmark \quad$ Urine $\mathrm{pH}$ \\ $\checkmark \quad$ Urine volume \\ $\checkmark \quad$ Urinary substrate \\ $\checkmark \quad$ Full electrolyte panel \\ $\checkmark \quad$ Analysis of stone composition
}

Clinical Features ${ }^{(2)}$

i) Pain with urination

ii) Nausea or Vomiting

iii) Pain and burning sensation during urination.

iv) Fever

v) Cloudy or foul smelling urine 
vi) Pain in the back and side of ribs.

\section{Risk Factors}

- Family or personal history

- Dehydration

- Diet

- Obesity

- Digestive disease and surgery

- Various medications.

- Other medical condition

\section{Treatment}

As primary therapy for ureteric calculi, parenteral narcotics are used traditionally. But many studies shows that NSAIDS can be used in relieving pain by inhibition of several prostaglandinmediated pain pathway and also by reducing ureteral contractility.

\section{TAMSULOSIN}

It is a selective $\alpha_{1} \mathrm{~A}$ and $\alpha_{1} \mathrm{D}$-adrenoceptor antagonist. Prostatic capsule, prostatic urethra and bladder, prostate gland are predominated by $\alpha_{1}$ A receptors ${ }^{(11)}$. It has spasmolytic effect which increase the stone expulsion rate, decrease expulsion time and reduce the need for endoscopic procedure and hospitalization and provide good control of pain. ${ }^{(12)}$

\section{DEFLAZACORT}

Deflazacort has antiflammatory action and immunosuppressive activity. Deflazacort is an oxazoline derivative of prednisolone ${ }^{(13)}$. It reduces the inflammation thus reduces the obstacle for passage of stone and increases the expulsion rate when given in combination with Tamsulosin ${ }^{(14)}$. There is no studies describing the role of Deflazacort as single therapy in ureteric calculi.

Surgical procedure are needed depending on the size of stone. The procedures assessed by urologist are Ureteroscopy, or percutaneous nephrolithotomy, shock wave lithotripsy. The patients with failure of stone progression, increasing or unremitting colic, and persistent obstruction are mostly the candidates for surgical management. ${ }^{(15)}$

\section{MATERIALS AND METHOD}

\section{Data source:}

All the relevant information regarding the study was collected from case records and direct interview with patients and care givers. Data from case records and care givers was collected by 
using suitably designed proforma. The study was approved by Research and Ethical Committee of Cosmopolitan hospital, Trivandrum

\section{Study population:}

Patients were taken from Urology department of Cosmopolitan Hospital. Informed consent was obtained. The study was conducted for the period of 2 months.

\section{Assessment of QOL:}

Details were collected from case records of the patients with ureteric stone and direct interview with the patients and caregivers and recorded in Wisconsin Stone-QOL questionnaire.

\section{Assessment of efficacy of Tamsulosin and Deflazacort combination:}

By accessing whether the stone is expelled in patients after use of medication by using ultrasound reports and by directly interviewing patients for the improvement of quality of life using Wisconsin Stone-QOL.

\section{Statistical Analysis:}

Quantitative variables will be expressed as mean, standard deviation. Qualitative variable will be expressed as frequently and percentage. A p-value $<0.05$ will be considered statistically significant. Data analysis will be performed using SPSS software version 16.

\section{OBSERVATION AND RESULTS}

The proposed study entitled "The prospective study on evaluation of efficacy of combination therapy of Tamsulosin and Deflazacort in ureteric stone expulsion" was a prospective observational study carried out in a multispecialty tertiary care hospital. In our study we analyzed the data collected from 20 patients diagnosed with ureteric calculi. Study aimed to evaluate the efficacy of Tamsulosin and Deflazacort combination in expulsion of ureteric stone and also to access the improvement of quality of life of patients under medication by using Wisconsin Stone-QOL questionnaire.

\section{Demographic Details of the Patients}

In this section, the data related to demographic details of patients were collected and recorded.

\section{Percentage Distribution of Patients Based On Age}

The percentage of distribution of patients based on age is shown in following table;

Table 1: Percentage of patients based on age

\begin{tabular}{lll}
\hline Age & Frequency & Percentage \\
\hline$\leq 40$ & 6 & 30 \\
$40-60$ & 10 & 50 \\
$>60$ & 4 & 20 \\
Total & 20 & 100 \\
\hline
\end{tabular}




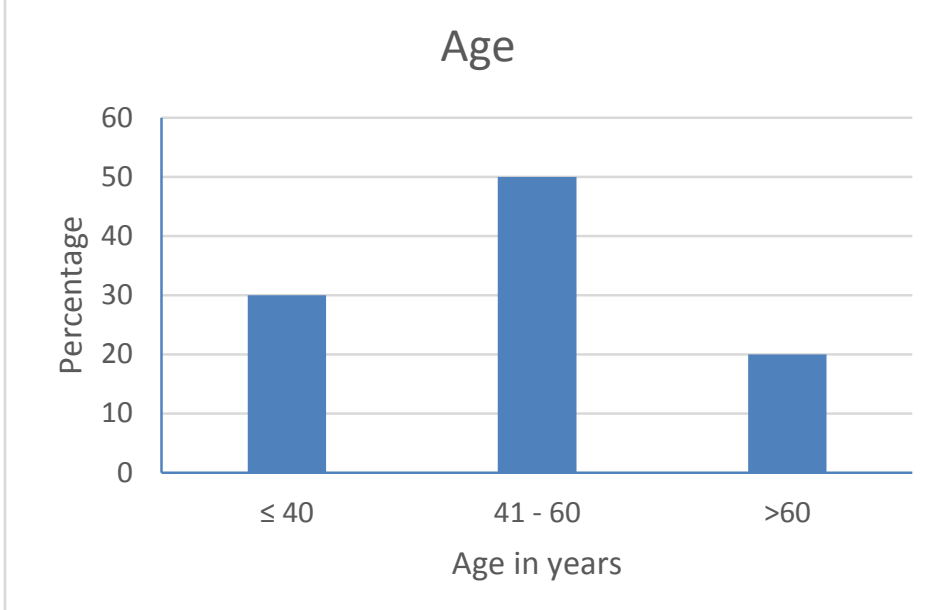

Figure 1: Diagrammatic representation of patients based on age

From the table 1, it was observed that out of total 20 patients frequency of occurrence of ureteric stone was $30 \%$ in patients above or equal 40 years of age and $50 \%$ in patients between the ages of 40-60 years. In patients with age above 60 years the frequency was found to be $20 \%$. Thus from this table we conclude that the occurrence of ureteric stone were higher between the age of 40-60.

\section{Percentage Distribution of Patients Based On Gender}

The percentage of distribution of patients based on gender is shown in the following table;

Table 2: Percentage of patients based on gender

\begin{tabular}{lll}
\hline Gender & Frequency & Percentage \\
\hline Male & 16 & 80 \\
Female & 4 & 20 \\
Total & 20 & 100 \\
\hline
\end{tabular}

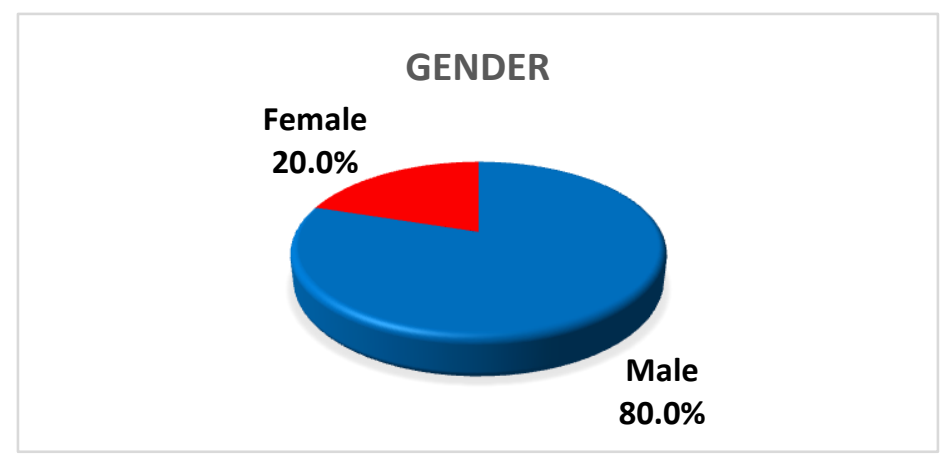

Figure 2: Diagrammatic representation of patients based on Gender

From the table 2, it was observed that out of the total number of patients with ureteric stone, $80 \%$ of patients involved in the study were male and $20 \%$ were females. Thus we conclude from the above table that the occurrence of ureteric stone are higher in male than females.

\section{Percentage Distribution of Patients Based On Marital Status}


The percentage of distribution of patients based on their marital status is show in the following table

Table 3: Percentage of patients based on their marital status

\begin{tabular}{lll}
\hline Marital status & Frequency & Percentage \\
\hline Unmarried & 2 & 10 \\
Married & 18 & 90 \\
Total & 20 & 100 \\
\hline
\end{tabular}

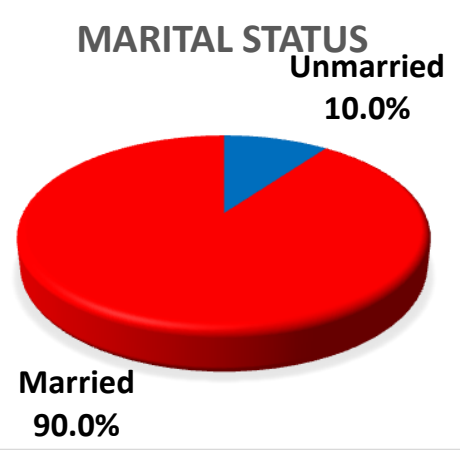

Figure 3: Diagrammatic representation of distribution of patients based on their marital status

From the Table 3, it was observed that out of 100 percentage of patients with ureteric stone involved in study, $90 \%$ of patients were married and $10 \%$ were unmarried. Thus from this we conclude that, in this pilot study the occurrence of ureteric stone is seen higher in married patients than unmarried.

\section{Percentage Distribution of Patients Based On Symptoms}

The percentage of distribution of patients based on symptoms is shown in following table

Table 4: Percentage distribution of patients based on symptoms

\begin{tabular}{lll}
\hline Presenting symptoms & Frequency & Percentage \\
\hline Pain & 20 & 100 \\
Burning micturition & 5 & 25 \\
Radiating pain & 8 & 40 \\
Hematuria & 4 & 20 \\
Nausea and vomiting & 9 & 45 \\
\hline
\end{tabular}




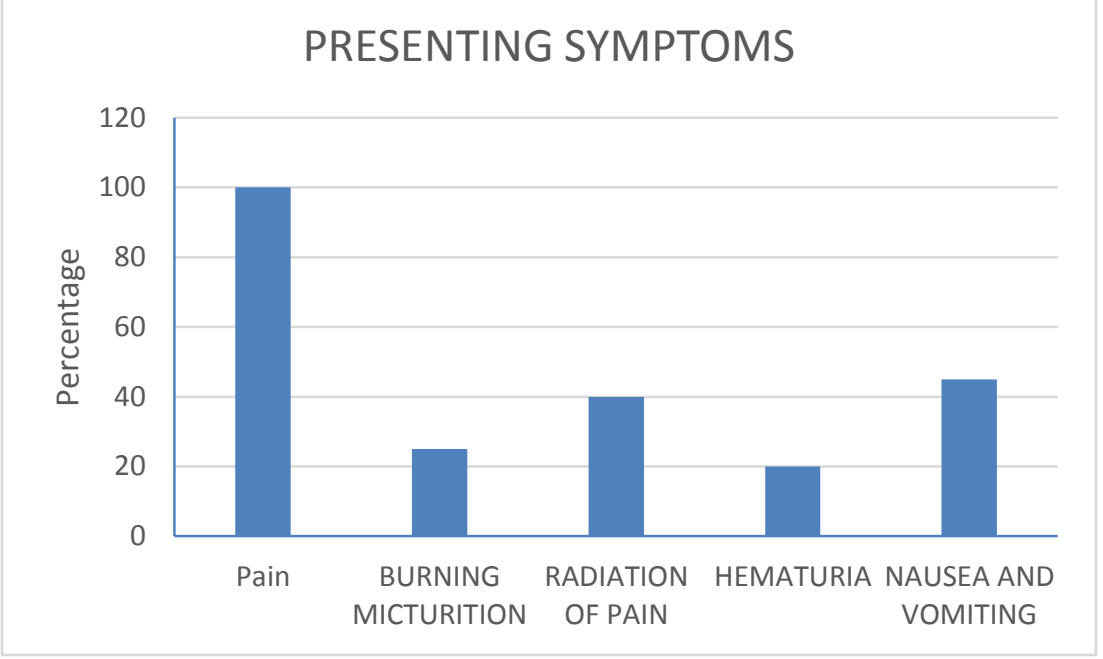

Figure 4: Diagrammatic representation of distribution of patients based on symptoms

From the Table 4 , it was observed that pain was experienced by $100 \%$ of patients involved in this study, $25 \%$ of patient had burning micturition, hematuria was experienced by $20 \%$ of patient in this study, nausea and vomiting were seen in $45 \%$ of patients and radiating pain was present in $40 \%$ of patient.

\section{Percentage Of Distribution Of Patients Based On Site Of Stone}

The percentage of distribution of patients based on site of stone is shown in following table

Table 5: Percentage distribution of patients based on site of stone

\begin{tabular}{lll}
\hline Site of stone & Frequency & Percentage \\
\hline Right vesicoureteric junction & 6 & 30 \\
Left vesicoureteric junction & 4 & 20 \\
Lower ureter & 3 & 15 \\
Upper ureter & 5 & 25 \\
Mid ureter & 2 & 10 \\
Total & 20 & 100 \\
\hline
\end{tabular}

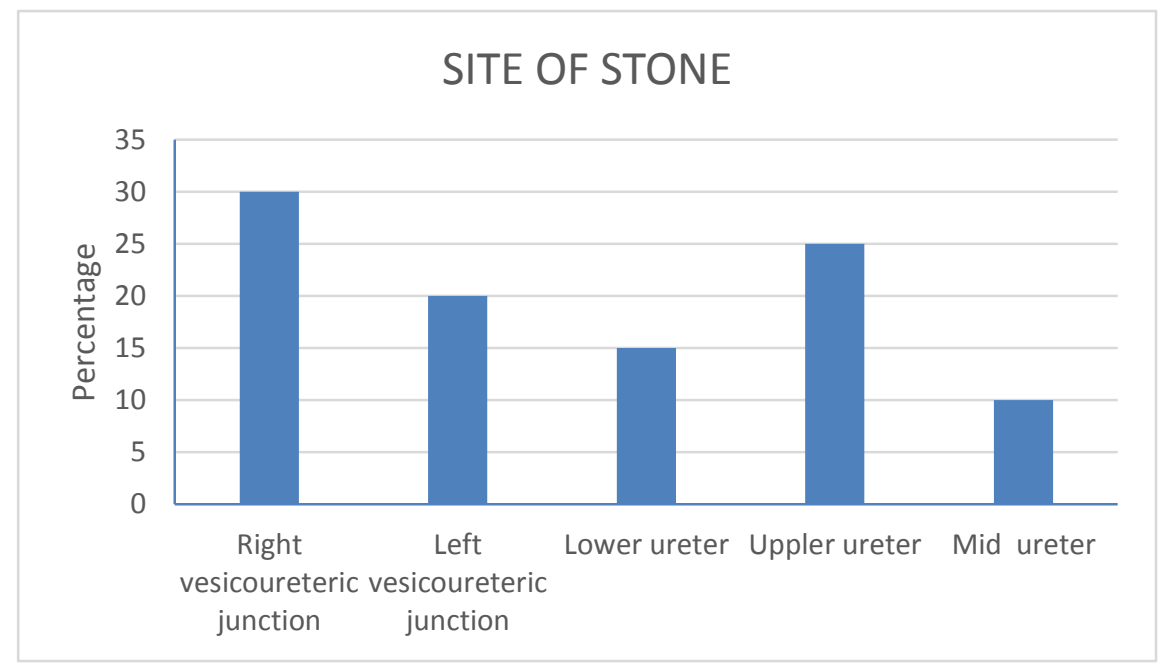

Figure 5: Diagrammatic representation of distribution of patients based on site of stone 
From the Table 5, it was observed that $30 \%$ of patients out of 20 patients involved in this study had the site of stone at the Right vesicoureteric junction, $20 \%$ of patient had left vesicoureteric junction as site of stone, lower ureter was the site of stone for $15 \%$ of patients and $25 \%$ and $10 \%$ of patient had upper ureter and mid ureter as the site of stone respectively. Thus we conclude from this table that vesicoureteric junction is the most common site of stone in this study.

\section{Percentage of Distribution of Patients Based On Size of Stone}

The percentage of distribution of patients based on size of stone is shown in following table

Table 6: Percentage distribution of patients based on size of stone

\begin{tabular}{lll}
\hline Size Of Stone (in mm) & Frequency & Percentage \\
\hline 2 & 1 & 5 \\
3 & 4 & 20 \\
4 & 6 & 30 \\
5 & 6 & 30 \\
6 & 3 & 15 \\
Total & 20 & 100 \\
\hline
\end{tabular}

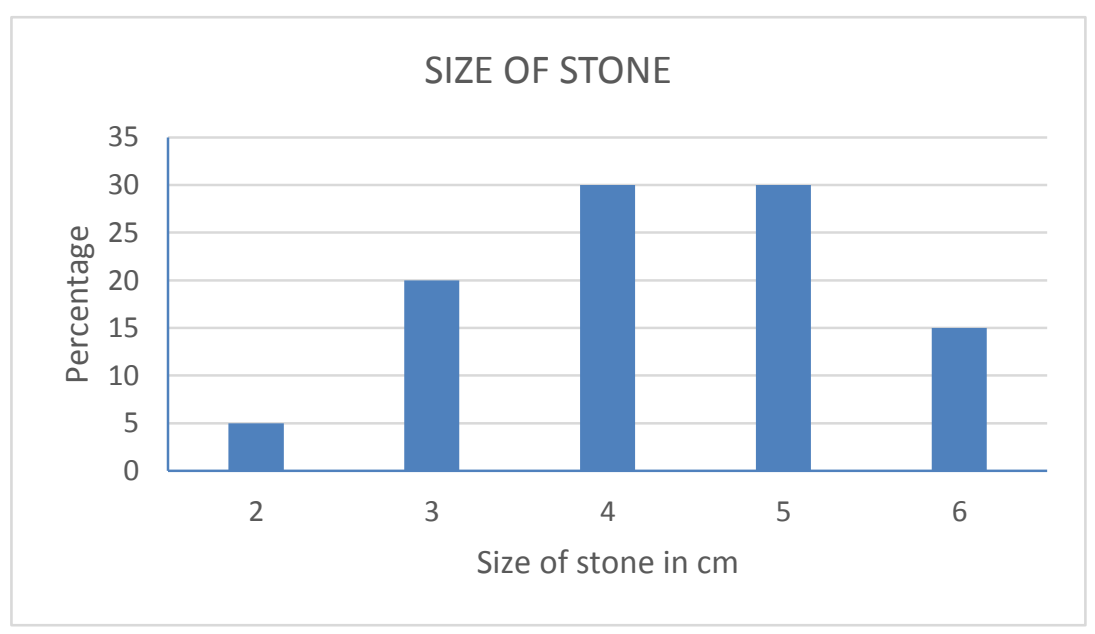

Figure 6: Diagrammatic representation of distribution of patients based on size of stone

From Table 6, it is clear that out of $100 \%$ of patient with ureteric calculi 30 percentage of patients had stone size $4 \mathrm{~mm}$ and $5 \mathrm{~mm}, 20 \%$ of patients had $3 \mathrm{~mm}$ as the stone size, $15 \%$ of patients has $6 \mathrm{~mm}$ stone and $5 \%$ of patients in the study had $5 \mathrm{~mm}$ stone. From this we conclude that majority of the patients had the stone size $4 \mathrm{~mm}$ and $5 \mathrm{~mm}$.

\section{Percentage Distribution Of Patients Based On Hydronephrosis}

The percentage distribution of patients based on hydronephrosis is shown in following table;

Table 7: Percentage distribution of patients based on hydronephrosis

\begin{tabular}{lll}
\hline Hydronephrosis & Frequency & Percentage \\
\hline Absent & 6 & 30 \\
Present & 14 & 70 \\
Total & 20 & 100 \\
\hline
\end{tabular}




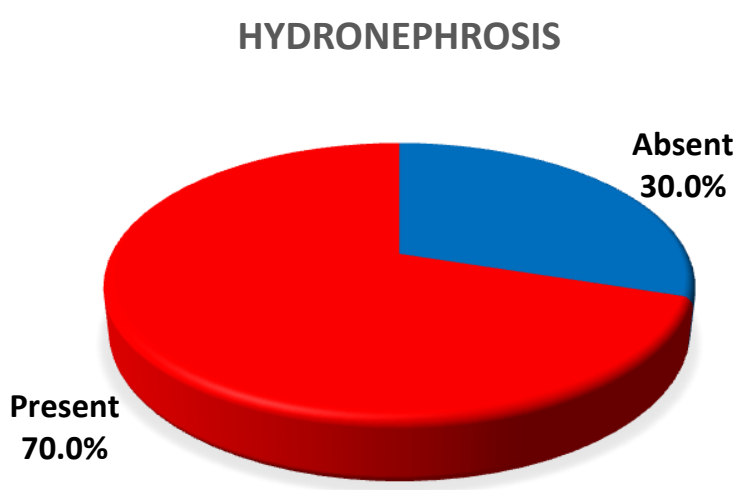

Figure 7: Diagrammatic representation of distribution of patients based on hydronephrosis From Table 7,it was observed that out of $100 \%$ of patients with ureteric stone $70 \%$ of them experienced hydronephrosis and only $30 \%$ is not experienced it.So we can conclude that majority of patients with ureteric stone will have hydronephrosis.

\section{PERCENTAGE DISTRIBUTION OF PATIENTS BASED ON COMORBIDITIES}

\section{PRESENT IN THEM}

The percentage distribution of patient's based on comorbidities present in them are shown below

Table 8: Percentage distribution of patients based on Comorbidities present in them

\begin{tabular}{lll}
\hline Comordidities & Frequency & Percentage \\
\hline Hypertension & 7 & 35 \\
Dyslipidemia & 5 & 25 \\
Diabetes & 4 & 20 \\
Thyroid & 1 & 5 \\
Respiratory disease & 1 & 5 \\
Liver disease & 2 & 10 \\
Heart disease & 4 & 20 \\
\hline
\end{tabular}

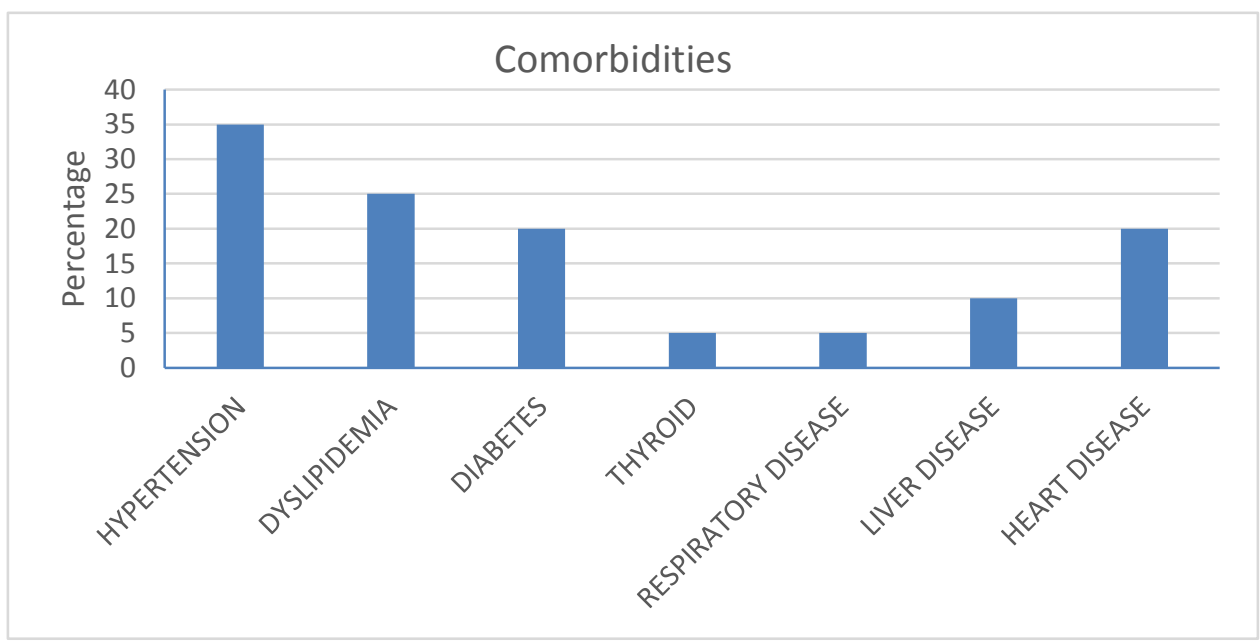

Figure 8: Diagrammatic representation of distribution of patients based on Comorbidities present in them 
From Table 8 , it shows that $35 \%$ of patients experience hypertension, $25 \%$ have dyslipidemia, $20 \%$ with diabetes, $5 \%$ experience both thyroid and respiratory disease, $10 \%$ with liver disease and $20 \%$ with heart disease.

\section{Percentage Distribution Of Patients Based On Their Social History}

The percentage distribution of patients based on their social histories are shown below;

Table 9: Percentage distribution of patients based on their Social history

\begin{tabular}{lll}
\hline Social history & Frequency & Percentage \\
Smoking & 6 & 30 \\
Alcoholism & 6 & 30 \\
\hline
\end{tabular}

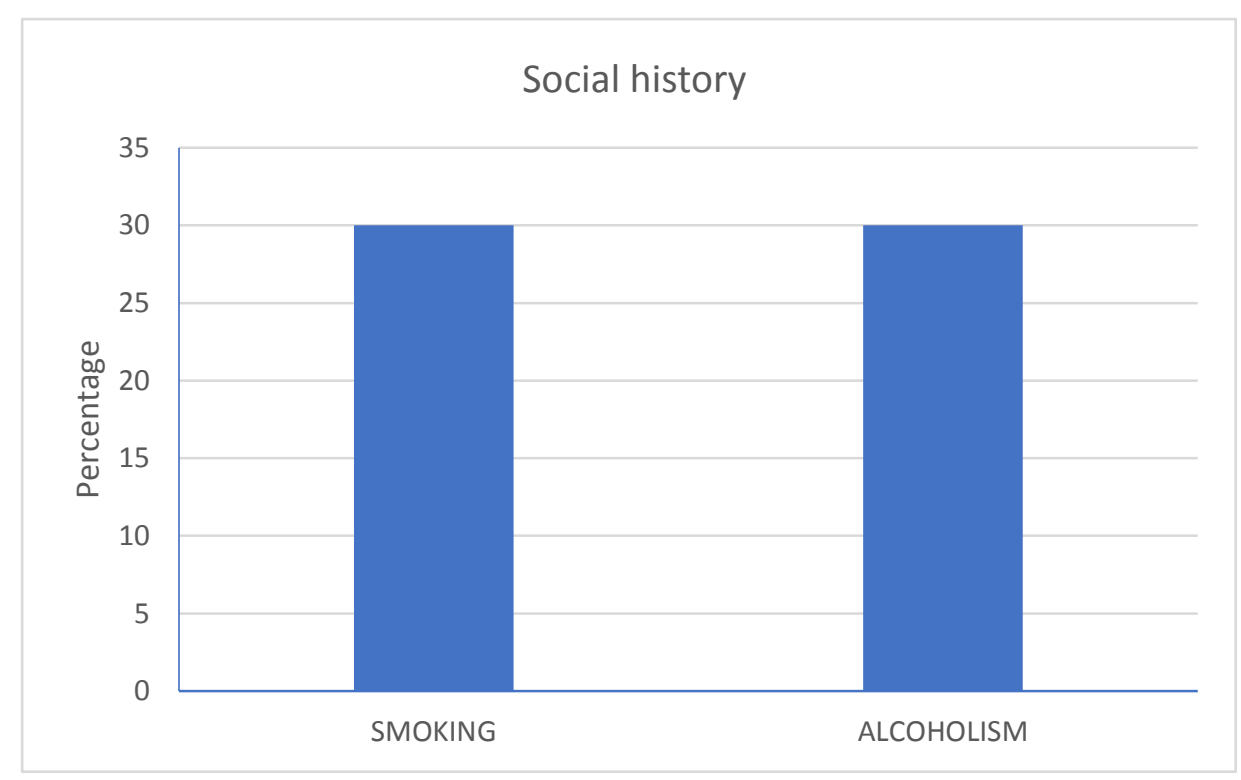

Figure 9: Diagrammatic representation of distribution of patients based on their Social history

From the Table 9, it shows that out of 20 patients participate in this study, $30 \%$ of them have smoking habit and $30 \%$ of them having alcohol intake habit.

Percentage Distribution of Patients Based On Their Ability To Take Medicines That Were Prescribed

The percentage distribution of patients based on their ability to take medicines as prescribed are shown below;

Table 10: Percentage distribution of patients based on their ability to take medicines as prescribed

\begin{tabular}{lll}
\hline Able to take the medicines as Prescribed & Frequency & Percentage \\
\hline Yes & 20 & 100 \\
\hline
\end{tabular}

From the Table 10, it indicate that out of 20 patients in this study $100 \%$ of them are able to take the prescribed medicines. 
Percentage Distribution of Patients Based On Their Need or Help to Take Their Medicines That Were Prescribed

The percentage distribution of patients based on their need or help to take their prescribed medicine are as follows;

Table 11: Percentage distribution of patients based on their need or help to take their prescribed medicines

\begin{tabular}{lll}
\hline Does anyone else help you to take your medication & Frequency & Percentage \\
\hline Absent & 17 & 85 \\
Present & 3 & 15 \\
Total & 20 & 100 \\
\hline
\end{tabular}

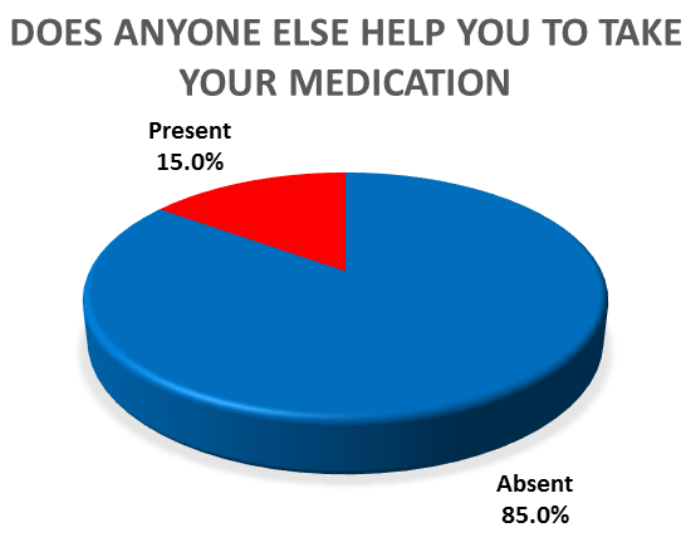

Figure 10: Diagrammatic representation of distribution of patients based on their need or help to take their prescribed medicines

From Table 11, it is observed that out of $100 \%$ patients enroll in the study, $85 \%$ patients do not require any help in taking medicines but $15 \%$ of them require help of others to take their prescribed medicines.

Percentage Distribution of Patients Based On the Efficacy of Medicines That Were Prescribed

The percentage distribution of patients based on the efficacy of prescribed medicine are as follows;

Table 12: percentage distribution of patients based on the efficacy of prescribed medicines

\begin{tabular}{lll}
\hline Medication is effective & Frequency & Percentage \\
\hline No & 4 & 20.0 \\
Yes & 16 & 80.0 \\
Total & 20 & 100.0 \\
\hline
\end{tabular}




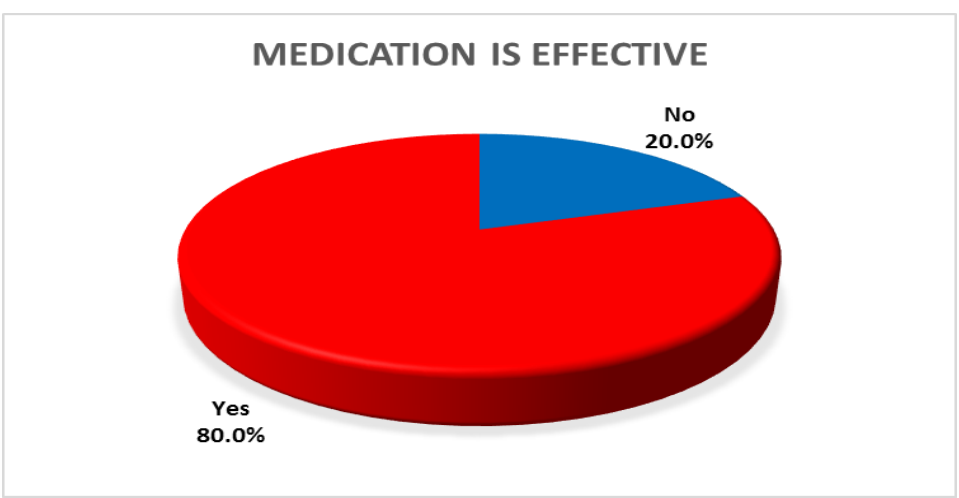

Figure 11: Diagrammatic representation of distribution of patients based on efficacy of prescribed medicines

From Table 12, it is shown that $80 \%$ of total patient is benefited with the medicines but $20 \%$ of them suggest that the medicine is not effective.

Percentage Distribution of Patients Based On Dependancy for Their Daily Living Activities The percentage distribution of patients based on their dependency for their daily living are as follows;

Table 13: Percentage distribution of patients based on dependency for their daily living

\begin{tabular}{lll}
\hline Dependent for activities of daily living & Frequency & Percentage \\
\hline No & 17 & 85 \\
Yes & 3 & 15 \\
Total & 20 & 100 \\
\hline
\end{tabular}

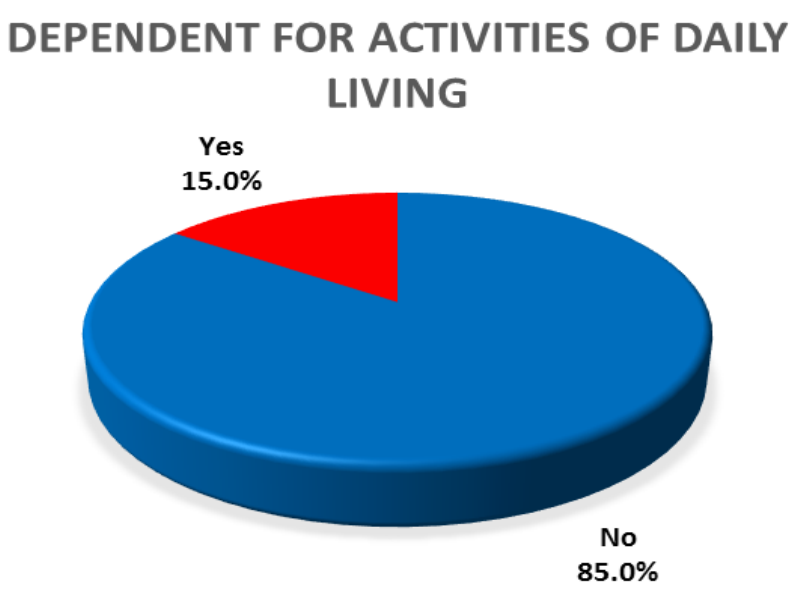

Figure 12: Diagrammatic representation of distribution of patients based on dependency for their daily living

From Table 12, it shows that, out of $100 \%$ patients $15 \%$ patients enroll in the study are dependent for their daily activities whereas $85 \%$ of them are not dependent.

Percentage distribution of patients based on site of stone (expulsion rate) during follow up The percentage distribution of patients based on site of stone during follow up are as follows 
Table 14: Percentage distribution of patients based on site of stone during follow up

\begin{tabular}{lll}
\hline Expulsion rate & Frequency & Percentage \\
\hline Stone Expelled & 16 & $80 \%$ \\
Stone Present & 4 & $20 \%$ \\
Site Of Stone Present & & \\
Left vesicoureteric region & 2 & 10.0 \\
Lower ureter & 1 & 5.0 \\
Upper ureter & 1 & 5.0 \\
Total & 20 & 100 \\
\hline
\end{tabular}

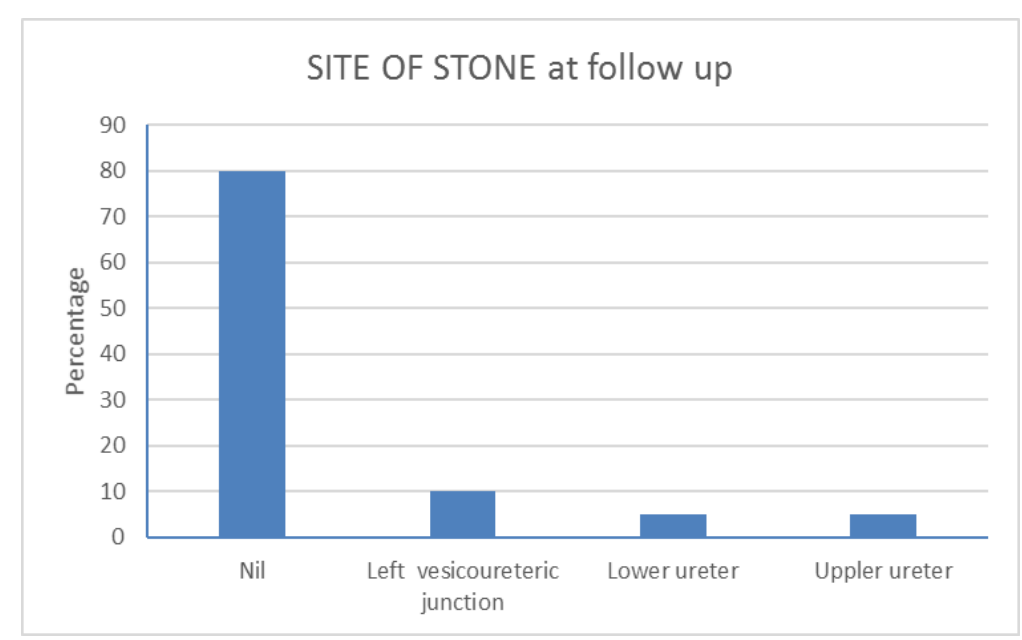

*Nil-Stone expelled (80\%)

Figure 13: Diagrammatic representation of distribution of patients based on site of stone during follow up

From Table 14, it was observed that out of $100 \%$, only $10 \%$ of patients have present stone in left vesicoureteric junction, $5 \%$ of them have stone on both lower ureter and upper ureter and it also indicate that $80 \%$ of the patients involved in the study has expelled the stone. Thus we can conclude that the combination drug Tamsulosin and Deflazacort are effective in expelling ureteric stone.

\section{Percentage Distribution of Patient's Based on Hydronephosis during Follow Up}

The percentage distribution of patients based on hydronephrosis during follow up are as follows;

Table 15: Percentage distribution of patients based on hydronephrosis during follow up

\begin{tabular}{lll}
\hline Hydronephrosis during follow up & Frequency & Percentage \\
\hline Absent & 16 & 80.0 \\
Present & 4 & 20.0 \\
Total & 20 & 100.0 \\
\hline
\end{tabular}




\section{HYDRONEPHROSIS AT FOLLOW UP}

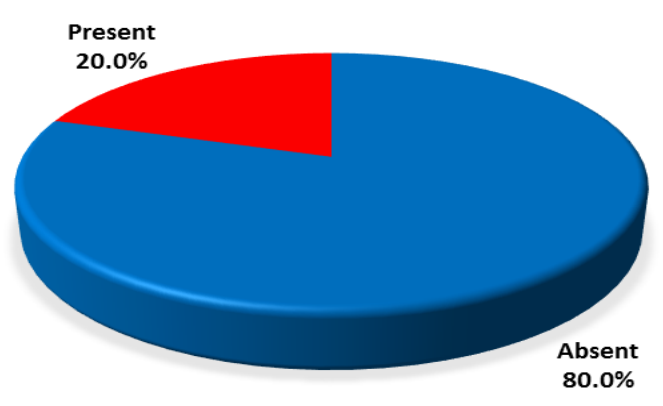

Figure 14: Diagrammatic representation of distribution of patients based on hydronephrosis during follow up

From Table 15, it shows that during follow-up of patients with ureteric stone enrolled in the study, $80 \%$ of them not experience any hydronephrosis after treatment but $20 \%$ of them still experience the hydronephrosis after treatment.

\section{Assessing Quality Of Life Based On Wisconsin QOL Scale}

In this section the data related to assessment of quality of life of patients with ureteric stone taking combination of Tamsulosin and Deflazacort is collected. The data's related to quality of life assessment before and after were collected and recorded. The collected data is shown in the following table.

The Wisconsin Stone Quality of Life Questionnaire (WISQOL) is a disease specific health related quality of life instrument which is designed to assess the impact on patients of stones in the urinary tract (i.e. urolithiasis)

\section{Comparison of Change In QOL Of Patient Before and After Treatment}

Table 16: Assessment of QOL Q1 before and after treatment with tamsulosin and Deflazacort combination in patient with ureteric stone

\begin{tabular}{llllll}
\hline & \multirow{2}{c}{ QOL Q1 } & \multicolumn{2}{c}{ Paired t test } \\
& & Mean & sd & t & p \\
\hline Before treatment & 20 & 9.3 & 3.3 & 8.31 & $<0.001$ \\
After treatment & 20 & 14.3 & 2.1 & & \\
\hline
\end{tabular}




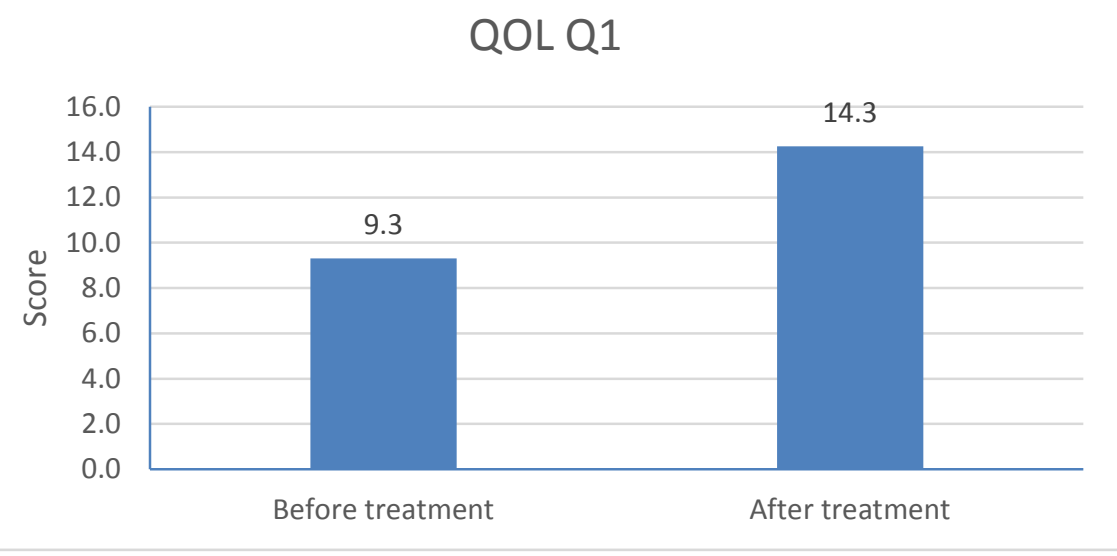

Figure 15: Comparison of change in QOL Q1 before and after treatment with combination of Tamsulosin and Deflazacort in patient with ureteric stone.

From the above table, the average QOL-Q1 before combination treatment was 9.3 \pm 3.3 and after combination treatment with Tamsulosin and Deflazacort was 14.3 \pm 2.1 . The patient energy and activity level is improved and not at all feeling tired. The observed difference was statistically significant $(\mathrm{p}<0.05)$. There was a significant improvement in the QOL Q1 after combination treatment with tamsulosin and Deflazacort.

Table 17: Assessment of QOL Q2 before and after treatment with combination of Tamsulosin and Deflazacort in patient with ureteric stone

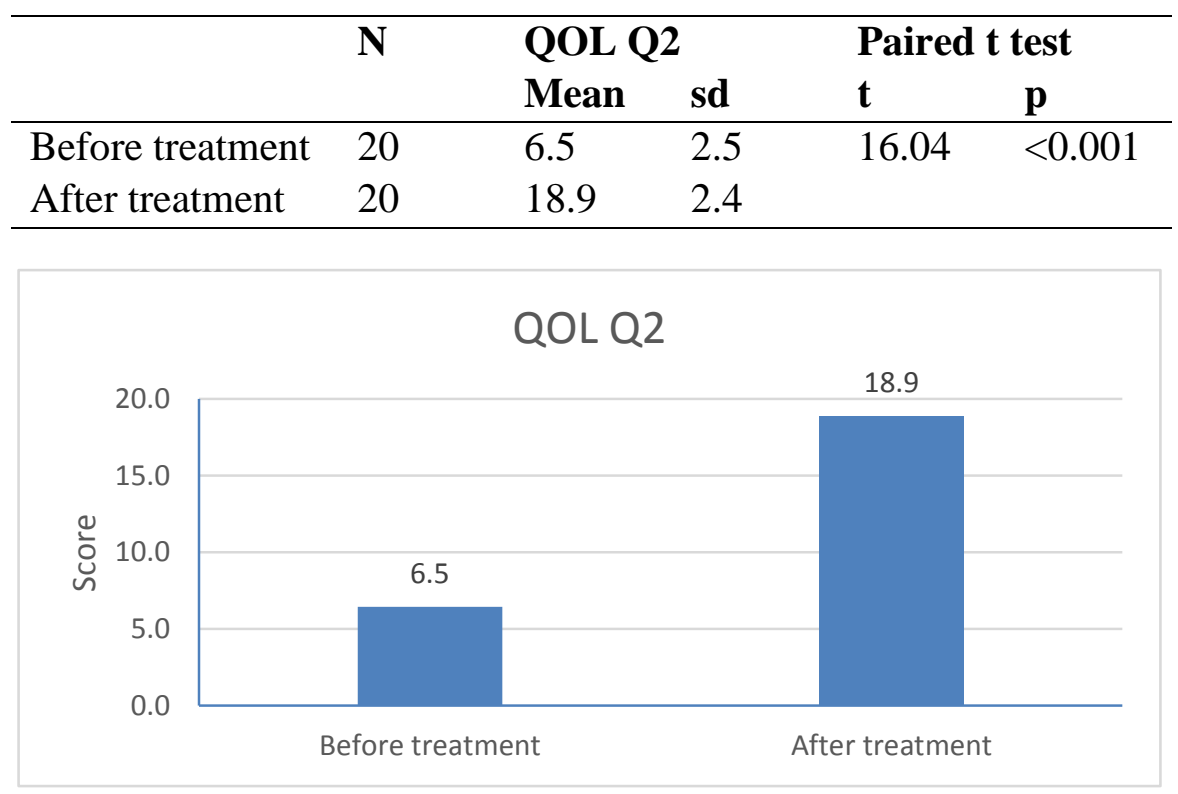

Figure 16: Comparison of change in QOL Q2 before and after combination treatment with Tamsulosin and Deflazacort in patient with ureteric stone.

From the above table, we found that the average QOL Q2 before treatment was $6.5 \pm 2.5$ and after

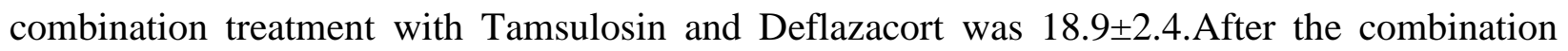
treatment there is no more trouble to getting sleep and difficulty returning to sleep and frequency 
of getting up to urinate while sleep is also diminished and also the quality of sleep is improved. The observed difference was statistically significant $(\mathrm{p}<0.05)$. There was a significant improvement in the QOL-Q2 of the patient after combination treatment with Tamsulosin and Deflazacort.

Table 18: Assessment of QOL Q3 of patient with ureteric stone before and after combination treatment with Tamsulosin and Deflazacort.

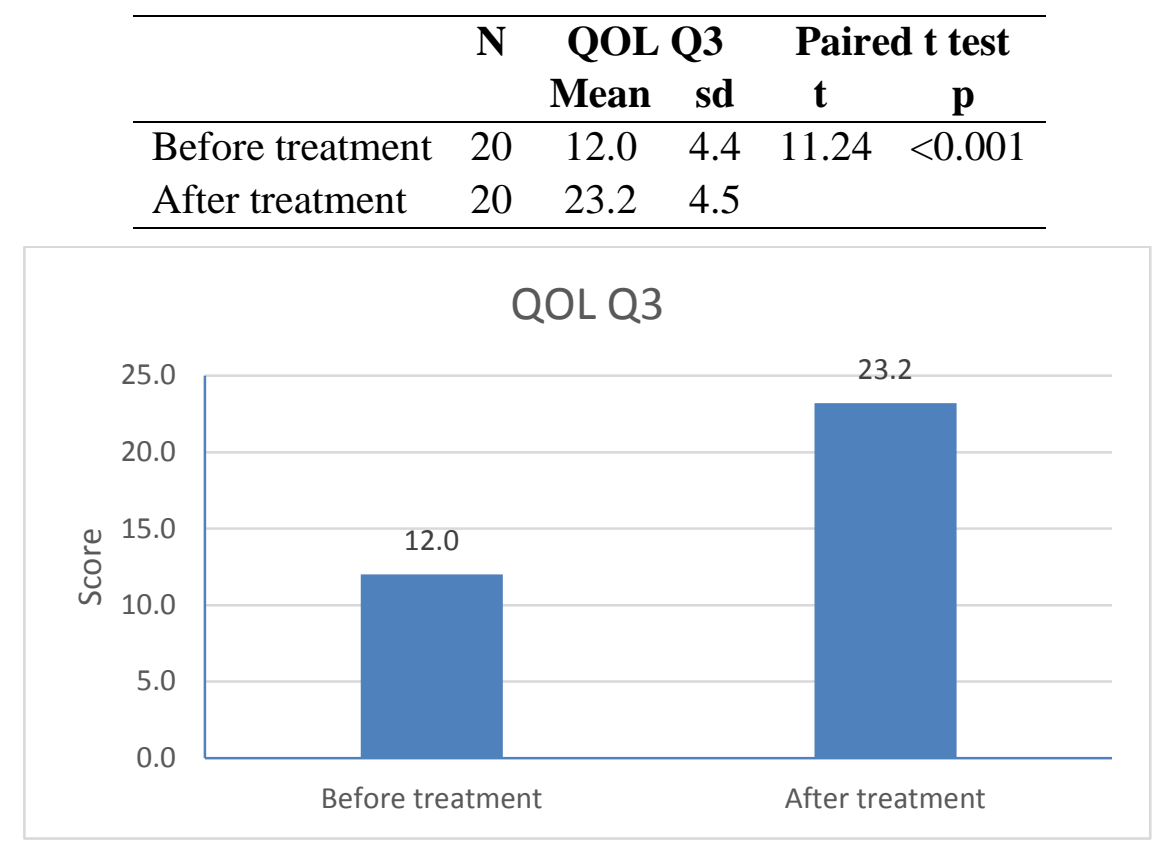

Figure 17: Assessment of QOL Q3 of patient with ureteric stone before and after combination treatment with Tamsulosin and Deflazacort.

From the above table, we found that the average QOL Q3 before treatment was $12.0 \pm 4.4$ and after combination treatment with Tamsulosin and Deflazacort was 23.2 \pm 4.5 . After the combination treatment there is no more lost leisure time and changing daily schedule, able to attend social events, and don't have to force themselves to go to work and focus were also improved. The observed difference was statistically significant $(\mathrm{p}<0.05)$. There was a significant improvement in the QOL Q3 of the patient after combination treatment with Tamsulosin and Deflazacort.

Table 19: Assessment of QOL Q4 of patient with ureteric stone before and after combination treatment with Tamsulosin and Deflazacort.

\begin{tabular}{llllll}
\hline & N & \multicolumn{2}{c}{ QOL Q4 } & \multicolumn{2}{c}{ Paired t test } \\
& & Mean & sd & t & p \\
\hline Before treatment & 20 & 11.1 & 2.4 & 10.17 & $<0.001$ \\
After treatment & 20 & 14.6 & 1.3 & & \\
\hline
\end{tabular}




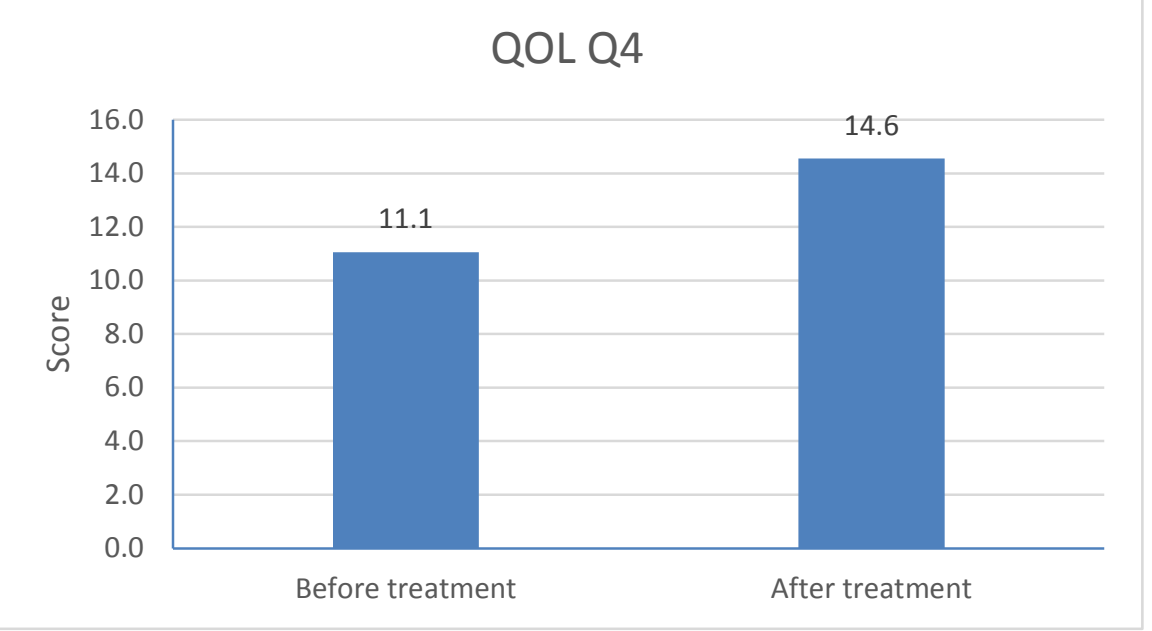

Figure 18: Comparison of QOL Q4 of patient with ureteric stone before and after combination treatment with Tamsulosin and Deflazacort.

From the above table, we found that the average QOL Q4 before treatment was $11.1 \pm 2.4$ and

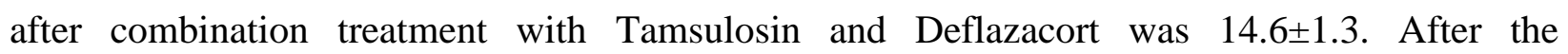
combination treatment there is no more difficulties in sticking with diet recommendations and in taking prescription medication as directed. And also reduced concern about general health. The observed difference was statistically significant $(\mathrm{p}<0.05)$. There was a significant improvement in the QOL Q4 of the patient after combination treatment with Tamsulosin and Deflazacort.

Table 20: Assessment of QOL Q5 of patient with ureteric stone before and after combination treatment with Tamsulosin and Deflazacort.

\begin{tabular}{llllll}
\hline & N & \multicolumn{2}{c}{ QOL Q5 } & \multicolumn{2}{c}{ Paired t test } \\
& & Mean & sd & t & p \\
\hline Before treatment & 20 & 4.7 & 1.3 & 30.11 & $<0.001$ \\
After treatment & 20 & 19.8 & 1.4 & & \\
\hline
\end{tabular}

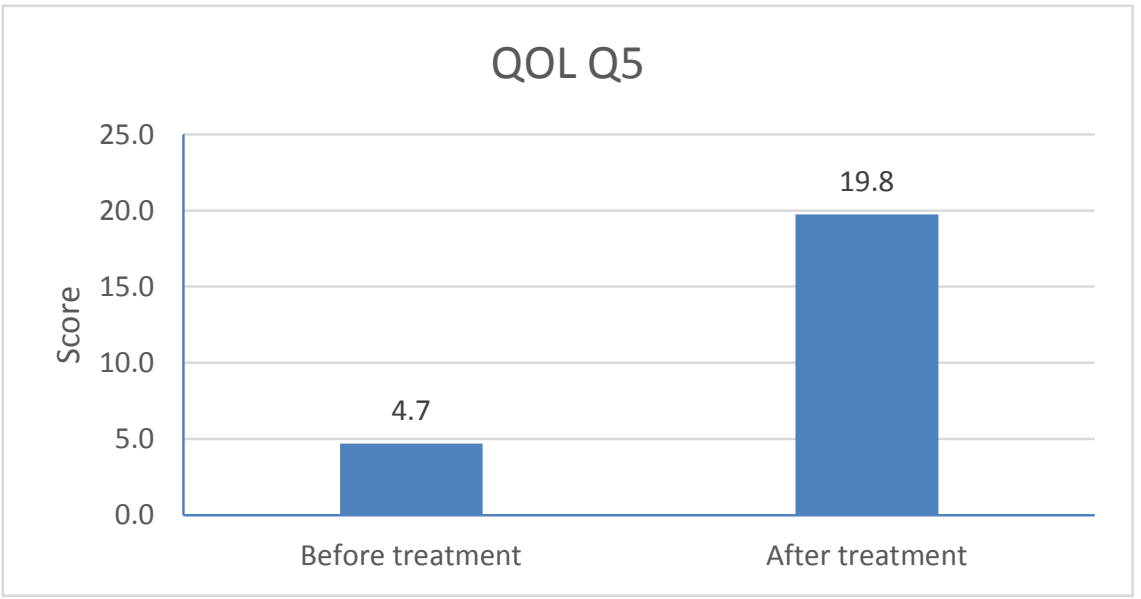

Figure 19: Comparison of QOL Q5 of patient with ureteric stone before and after combination treatment with Tamsulosin and Deflazacort. 
From the above table, we found that the average QOL Q5 before treatment was $4.7 \pm 1.3$ and after combination treatment with Tamsulosin and Deflazacort was 19.8 \pm 1.4 . After the combination treatment there is no more physical pain and symptoms like nausea, stomach upset and also diminished urinary frequency and urinary urgency. The observed difference was statistically significant $(\mathrm{p}<0.05)$. There was a significant improvement in the QOL Q5 of the patient after combination treatment with Tamsulosin and Deflazacort.

Table 21: Assessment of QOL Q6 of patient with ureteric stone before and after combination treatment with Tamsulosin and Deflazacort.

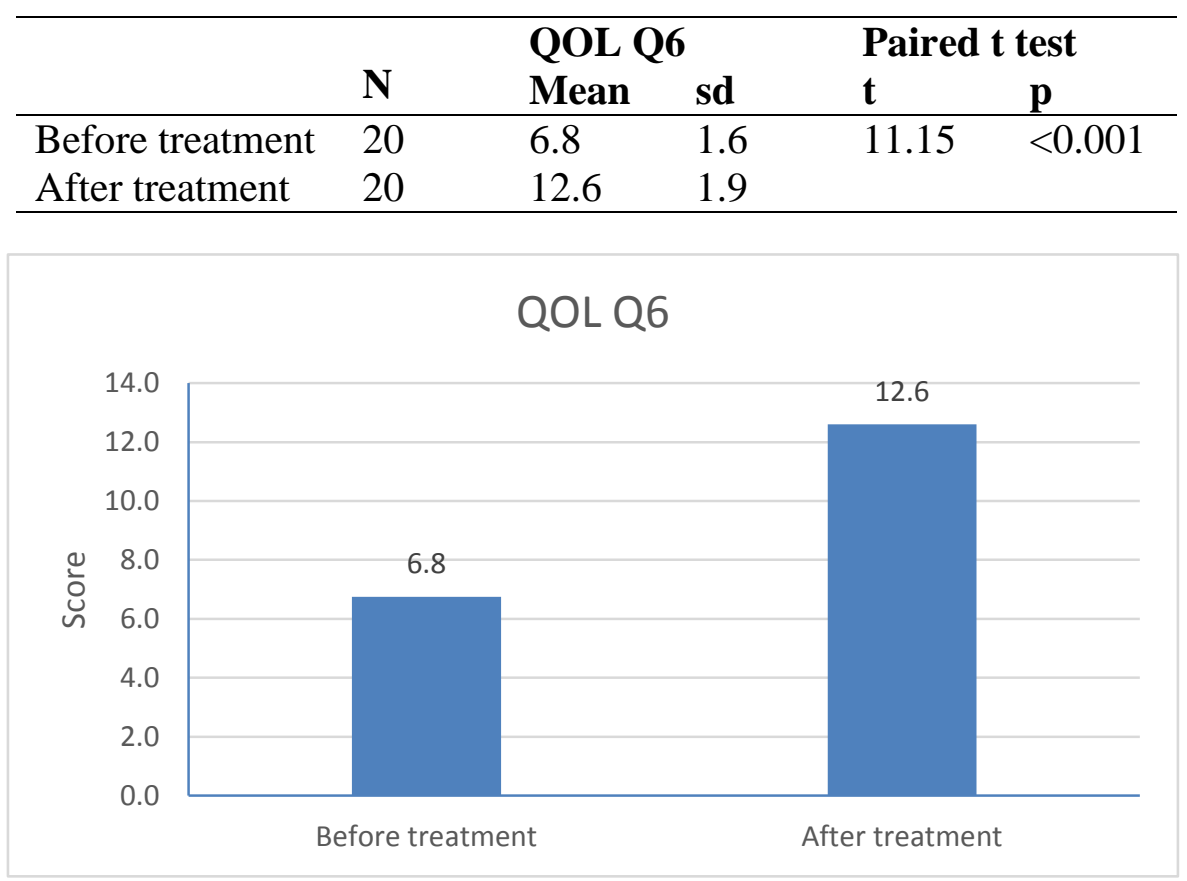

Figure 20: Comparison of QOL Q6 of patient with ureteric stone before and after combination treatment with Tamsulosin and Deflazacort.

From the above table, we found that the average QOL Q6 before treatment was $6.8 \pm 1.6$ and after combination treatment with Tamsulosin and Deflazacort was 12.6 \pm 1.9 . After the combination treatment there is no more need to make special arrangements when travelling and have improved interest in sexual life and being around others. The observed difference was statistically significant $(\mathrm{p}<0.05)$. There was a significant improvement in the QOL Q6 of the patient after combination treatment with Tamsulosin and Deflazacort.

Table 22: Assessment of QOL Q7 of patient with ureteric stone before and after combination treatment with Tamsulosin and Deflazacort.

\begin{tabular}{llllll}
\hline & N & \multicolumn{2}{c}{ QOL Q7 } & \multicolumn{2}{c}{ Paired t test } \\
\cline { 3 - 6 } & & Mean & sd & t & p \\
Before treatment & 20 & 18.2 & 4.0 & 10.52 & $<0.001$ \\
After treatment & 20 & 28.5 & 2.3 & & \\
\hline
\end{tabular}




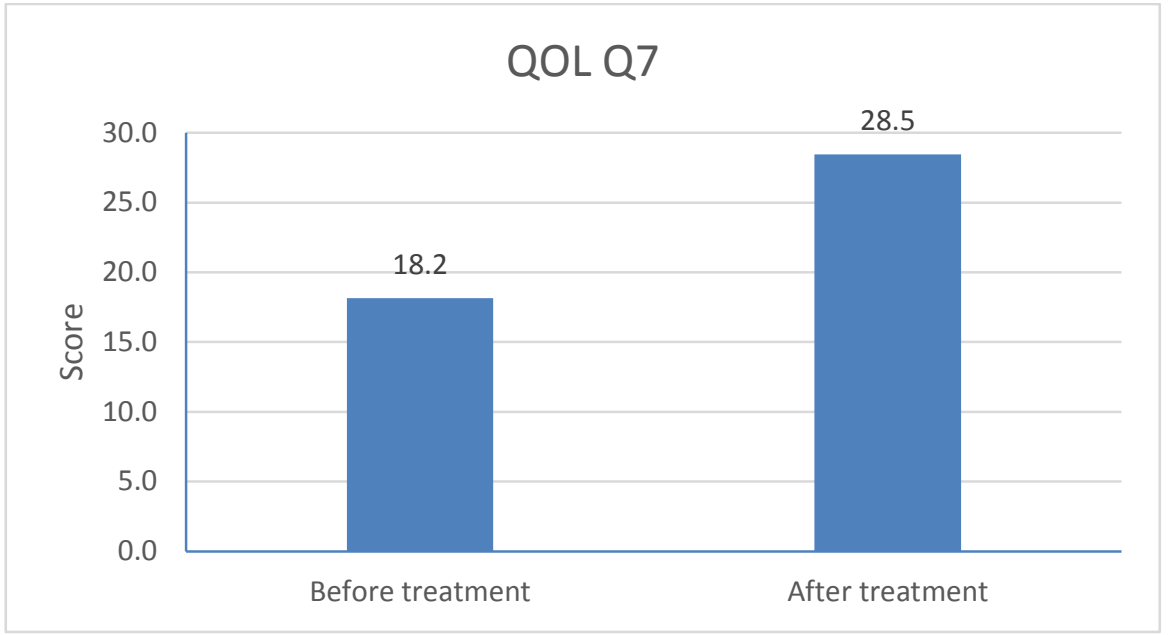

Figure 21: Comparison of QOL Q7 of patient with ureteric stone before and after combination treatment with Tamsulosin and Deflazacort.

From the above table, we found that the average QOL Q7 before treatment was $18.2 \pm 4.0$ and after combination treatment with Tamsulosin and Deflazacort was 28.5 \pm 2.3 . After the combination treatment there is no more feeling of frustration and worries and inconveniences of the situation. Reduced anxiety and irritability. The ability is also improved. The observed difference was statistically significant $(\mathrm{p}<0.05)$. There was a significant improvement in the QOL Q7 of the patient after combination treatment with Tamsulosin and Deflazacort.

\section{DISCUSSION}

This study is conducted with the objective to assess the efficacy of Tamsulosin and Deflazacort combination in ureteric stone expulsion and also to determine whether the use of this combination therapy improve the health quality of life of the patients using Wisconsin StoneQOL questionnaire.

Tamsulosin is a selective alpha $1 \mathrm{~A}$-and alpha $1 \mathrm{D}$-adrenoceptor antagonist. These $\alpha 1$-receptors are predominant in the prostatic urethra and bladder, prostate, prostatic capsule. The relaxation of prostate and bladder smooth muscles can aid expulsion of stone.

Deflazacort is an oxazoline derivative of prednisolone and it has an anti-inflammatory activity. It decreases the inflammation which further reduces the obstacle of passage stone and thus increases the expulsion rate when given in combination with Tamsulosin.

In this pilot study, 20 patients who were diagnosed with ureteric calculi, Tamsulosin and Deflazacort combination were prescribed was selected and statistical analysis was done using paired $t$ test and detailed analysis was performed.

This pilot study showed that the prevalence of ureteric stone was high in males than in females. The results was similar to that of the study conducted by Kiriaki K. Stamatelou et.al. ${ }^{(16)}$ 
In this study, it concluded that among the 20 patients treated with combination therapy of Tamsulosin and Deflazacort 16 of them (80\%) expelled the stone and 4 of them (20\%) not .But for those $20 \%$ patients the size of stone becomes smaller when compared to pre-treatment. The combination therapy used in this study is more efficient to expel the ureteric stone. The observations obtained in this study is similar to the study conducted by Dr.Anjana Gandhi et.al, on "Role of Deflazacort and Tamsulosin in Medical Expulsive Therapy for Symptomatic Lower Ureteric Stone: A Study Done in Rims, Ranchi”. In their study they stated that the expulsion rate of stone with combination therapy of Tamsulosin and Deflazacort is $89 \%$ compared to $80 \%$ with Tamsulosin alone. Also they stated that the expulsion time with the combination therapy was also short. ${ }^{(17)}$

The study conducted by Francesco Porpiglia et.al on "Corticosteroids and Tamsulosin in the Medical Expulsive Therapy for Symptomatic Distal Ureter Stones: Single Drug or Association?” also indicates that the $\alpha_{1}$-blockers (Tamsulosin) in association with corticosteroids (Deflazacort) are the most effective therapy, with higher expulsion rate over a short period of time. ${ }^{(14)}$

In the present study, the patient receiving combination therapy of Tamsulosin and Deflazacort, reported a significantly better QOL and pain relief, and no more symptoms like nausea, stomach upset and significantly reduced urinary frequency and urgency scores, reduced frustration and worries and inconveniences of the situation. No more difficulties sticking with diet recommendations and in taking prescription medication as directed. Reduced anxiety and irritability, and are able to attend social events and are more focused after the combination therapy with Tamsulosin and Deflazacort. In the similar study made by Dellabella et al.2004 similar improvement in QOL is observed. Dellabella $\mathrm{M}$ et al., evaluated the efficacy of combination therapy of Tamsulosin and Deflazacort in ureteric stone patients and are reported that the combination therapy of Tamsulosin and Deflazacort in patients with ureteric stone had a significantly increased stone expulsion rate, a shorter stone expulsion time, no drug related side effects and shorter hospital stays. ${ }^{(18)}$

\section{CONCLUSION}

By evaluating this pilot study, we conclude that the medical expulsive therapy using Tamsulosin and Deflazacort combination is a first line therapy in management of ureteric stones. It is also found that the combination therapy of Tamsulosin and Deflazacort have good expulsion rate.

\section{REFERENCES}

1. Sinha AR, Siwach V. Evaluation of the Efficacy of Tamsulosin and Deflazacort versus Tamsulosin Alone in Expulsion of Lower Ureteric Stones in a Tertiary Center. Int J Sci 
Stud 2019;6(10):68-72

2. Michelle R. Carter,Brad R. Green, Renal calculi: emergency department diagnosis and treatment

3. Parks J, Coe F, Favus M. Hyperparathyroidism in nephrolithiasis. Arch Intern Med. 1980; 140(11):1479-1481.

4. Burtis WJ, Brady TG, Orloff JJ, et al. Immunochemical Characterization of circulating parathyroid hormone-related, Protein in patients with humoral hypercalcemia of cancer. N Engl J Med. 1990; 322(16):1106-1112.

5. Breslau NA, Preminger GM, Adams BV, et al. Use of Ketoconazole to probe the pathogenetic importance of 1,12-dihydroxyvitamin D in absorptive hypercalciuria. J Clin Endocrinol Metab. 1992; 75(6):1446-1452.

6. Griffith DP, Osborne CA. Infection (urease) stones. Miner Electrolyte Metab. 1987; 13(4):278-285.

7. Pak CY, Sakhaee K, Moe O, et al. Biochemical profile of stone-forming patients with diabetes mellitus. Urology. 2003; 61(3):523-527.

8. Pak CY, Poindexter JR, Adams-Huet B, et al. Predictive value of kidney stone composition in the detection of metabolic abnormalities. Am J Med. 2003; 115(1):26-32.

9. Sakhaee K, Adams-Huet B, Moe OW, et al. Pathophysiologic basis for normouricosuric uric acid nephrolithiasis. Kidney Int. 2002; 62(3):971-979.

10. T. Vijaya, M. Sathish Kumar, N. V. Ramarao, et.al. Urolithiasis and Its Causes- Short Review. The Journal of Phytopharmacology 2013; 2(3): 1-6

11. Christopher J. Dunn, A Review of its Pharmacology and Therapeutic Efficacy in the Management of Lower Urinary Tract Symptoms, Drugs \& Aging volume 19, pages135$161(2002)$

12. Marco Dellabella e.tal. Efficacy of tamsulosin in medical management of juxtavesical ureteral stone, journal of urology (2003)

13. Anthony Markham, Harriet M Bryson, Deflazacort : A Review of its Pharmacological Properties and Therapeutic Efficacy, Drugs 50 (2), 317-333, 1995

14. Francesco Porpiglia e.tal., Corticosteroids and Tamsulosin in the Medical Expulsive Therapy for Symptomatic Distal Ureter Stones: Single Drug or association.

15. M Marberger e.tal. Management of Ureteric Stones , Eur Urol 1994;25:265-272

16. Kiriaki K.Stamatelou e.tal. Time trends in reported prevalence of kidney stones in the United States. 
17. Dr.Anjana Gandhi, Dr.Utkrisht Kant, Dr.Deepak Chandra Prakash. Role of Deflazacort and Tamsulosin in Medical Expulsive Therapy for Symptomatic Lower Ureteric Stone: A Study Done in Rims, Ranchi, IOSR Journal of Dental and Medical Sciences (IOSRJDMS) vol 16.no.10.2017.pp.67-69.

18. Dellabella M, Milanese G, Muzzonigro G. Medical-expulsive therapy for distal Ureterolithiasis: Randomized prospective study on role of corticosteroids used in combination with tamsulosin-simplified treatment regimen and health-related Quality of life. Urology. 2005; 66(4):712-15. Doi:10.1016/j.urology.2005.04.055.

AJPHR is

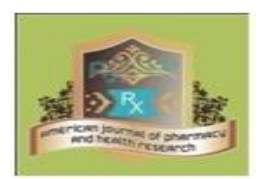

Peer-reviewed monthly

Rapid publication

Submit your next manuscript at editor@ajphr.com / editor.ajphr@gmail.com 